\title{
PERBANDINGAN AKTIVITAS REPELAN ANTARA KRIM MINYAK ATSIRI JAHE (Zingiber offinale, Roxb) DENGAN KRIM MINYAK ATSIRI SERE (Cymbopogon citratus (D.C) Stapf) TERHADAP NYAMUK Aedes aegypti BETINA
}

\section{THE COMPARATION OF REPELLENT ACTIVITIES BETWEEN GINGER (Zingiber offinale, Roxb) AND SERE (Cymbopogon citratus (D.C) Stapf) ESSENTIAL OIL CREAM OF Aedes aegypti FEMALE MOSQUITO}

\author{
Azis Ikhsanudin \\ Fakultas Farmasi Universitas Ahmad Dahlan \\ Jl. Prof. Dr. Soepomo, Janturan, Yogyakarta \\ Email: azisikhsanudin@yahoo.com
}

\begin{abstract}
ABSTRAK
Salah satu upaya pencegahan demam berdarah adalah mencegah gigitan nyamuk dengan menggunakan sediaan repelan. Sifat ketoksikan repelan sintetis menjadi alasan untuk dilakukan penelitian yang berasal dari tanaman. Sere dan jahe menjadi salah satu tanaman alternatif repelan alami karena memiliki kandungan minyak atsiri yang cukup tinggi. Tujuan penelitian ini adalah mengetahui perbandingan kemampuan efek repelan dari krim minyak atsiri sere (Cymbopogon citratus (D.C) Stapf) dan rimpang jahe (Zingiber officinale Roxb). Minyak atsiri daun sere (Cymbopogon citratus (D.C) Stapf) dan rimpang jahe (Zingiber officinale Roxb) diperoleh dengan cara destilasi uap air yang kemudian diformulasikan dalam basis krim. Konsentrasi minyak atsiri sere dalam krim sebesar 20\%v/b (FI); 30\%v/b; 40\%v/b (FIII), sedangkan konsentrasi minyak atsiri jahe dalam krim sebesar 6,25\%v/b (FIV); 12,5\%v/b (FV) dan 25\%v/b (FVI). Selanjutnya krim dievaluasi sifat fisiknya meliputi uji viskositas, uji daya lekat dan daya sebar serta uji daya repelan terhadap nyamuk Aedes aegypti betina sebanyak 20 ekor per kandang dengan probandus tangan relawan berjenis kelamin wanita sebanyak 4 orang. Data dianalisis dengan menggunakan statistik SPSS. Hasil penelitian menunjukkan krim dengan konsentrasi minyak atsiri sere $40 \% \mathrm{v} / \mathrm{b}$ (FIII) memiliki hasil yang lebih baik dibandingkan krim jahe dengan daya lekat 0,46 $\pm 0,04$ detik; daya sebar 56,32 $\pm 14,78 \mathrm{~cm}^{2}$ dan daya repelan sebesar 3014,2 $\pm 20,16$ detik.
\end{abstract}

Kata Kunci : sere, jahe, minyak atsiri, repelan, Aedes aegypti.

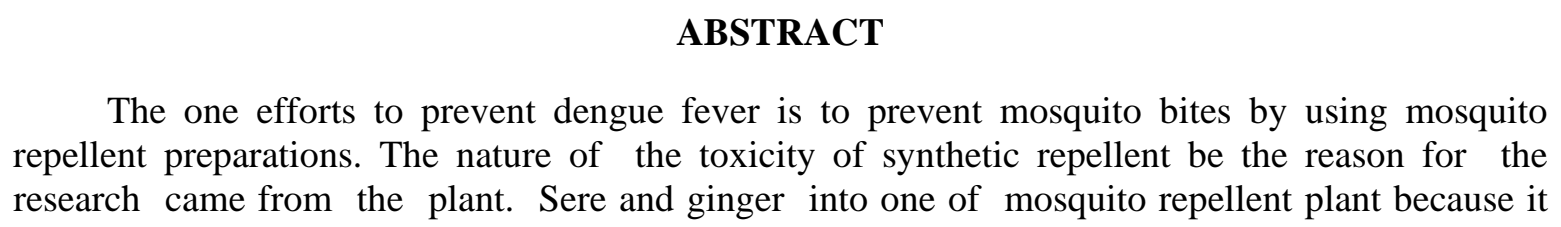


contains of natural essential oils are many. The aim of this study was to determine the comparative ability repelan effects of essential oils cream sere (Cymbopogon citratus (DC) Stapf) and ginger (Zingiber officinale Roxb). The essential oil of sere (Cymbopogon citratus (DC) Stapf and ginger (Zingiber officinale Roxb), obtained by isolation of leaves and rhizome by steam distillation of water which is then tested physical properties including test of adhesion, test of spreadability and test of mosquito repellent activities. The test of mosquito repellent activities using 20 birds Aedes aegypti mosquito female per cage with the using hand of women as volunteers as much as 4 people. In this study were divided into sixth formulas of test. The sixth of cream formula with variations in the concentration of essential oils sere and ginger wherein the formula I, II and III contain essential oils sere as much as $20 \% \mathrm{v} / \mathrm{w} ; 30 \% \mathrm{v} / \mathrm{w}$ and $40 \% \mathrm{v} / \mathrm{w}$, whereas for formula IV; V; and VI contain the essential oil of ginger as much as $6.25 \% \mathrm{v} / \mathrm{w} ; 12.5 \% \mathrm{v} / \mathrm{w}$ and $25 \% \mathrm{v} / \mathrm{w}$. Data of physical properties test were analyzed statistically using SPSS. The results showed the cream with the concentration of essential oils sere $40 \% \mathrm{v} / \mathrm{w}$ (FIII) have better outcomes than others formulas cream, where than of adhesion test is $0.46 \pm 0.04$ seconds; of the spreadibility test is $56.32 \pm 14.78$ $\mathrm{cm}^{2}$ and repellent effect of $3014.2 \pm 20.16$ seconds.

Key word : sere, ginger, essential oils, repellent, Aedes aegypti.

\section{PENDAHULUAN}

Angka kejadian penyakit yang disebabkan oleh vektor nyamuk di Indonesia cukup tinggi. Penyakit yang mendominasi antara lain adalah penyakit malaria yang disebabkan karena gigitan nyamuk Anopeles dan demam berdarah yang diakibatkan oleh gigitan nyamuk Aedes aegypti. Meningkatnya kondisi ini banyak disebabkan karena faktor kondisi iklim dan kebersihan lingkungan.

Dalam penanggulangan wabah demam berdarah dan malaria, salah satu pendekatan dalam pengendaliannya adalah dengan mencegah terjadinya kontak langsung antara manusia dengan nyamuk sebagi vektor atau pembawa. Upaya pencegahan gigitan nyamuk yang bersifat individu adalah dengan menggunakan sediaan repelan atau penolak nyamuk. Penggunaan repelan di masyarakat lebih disenangi karena kepraktisan dan kemudahan dalam penggunaannya. Sediaan repelan harus memenuhi persyaratan yaitu aman; (tidak menimbulkan efek samping) dan mampu melindungi kulit dari gigitan dan berkualitas (Yuliani, 2005).

Repelan yang beredar di pasaran mengandung bahan berbahaya, salah satunya adalah Diethyltoluamide (DEET). DEET bersifat korosif, dimana sediaan tersebut menyebabkan iritasi kulit serta dampak langsung akibat pemakaian repelan berbedabeda pada setiap individu, khususnya pada anakanak (Anonim,2007). Oleh karena itu perlu alternatif bahan aktif lain yang lebih aman. Salah satunya repelan yang sering digunakan oleh masyarakat adalah minyak atsiri dari tanaman.

Tanaman yang banyak dimanfaatkan oleh masyarakat adalah tanaman jahe dan sere. Sere (Cymbopogon citratus (D.C) Stapf) telah lama dimanfaatkan masyarakat sebagai repelan alami. Bau minyak atsiri khas yang dimiliki memungkinkan menghambat ketertarikan nyamuk terhadap bau keringat manusia. Demikian pula dengan Zingiber officinale, Penelitian menunjukkan bahwa kemampuan repelannya $85 \pm 1,8$ menit terhadap nyamuk 
P. Americana, 95 $\pm 1,3$ menit terhadap $B$.
Germanica dan 70,0 8,1 menit terhadap
$N$. Rhombifolia (Thavara, dkk., 2007).
Berdasarkan penelitian diatas maka perlu
dilakukan penelitian mengenai perbandingan
efek repelan sediaan vanishing cream minyak
atsiri sere dengan krim minyak atsiri jahe
sehingga diketahui potensi bahan alam untuk
pengembangan sediaan repelan alami.

\section{METODE PENELITIAN}

\section{Alat}

Alat yang digunakan: destilator uap dan air, alat-alat gelas, sangkar nyamuk serta aspirator. Untuk hewan uji yang digunakan adalah nyamuk Aedes aegypti betina usia 7-24 hari diambil dari laboratorium Parasitologi Fakultas Kedokteran UGM sebanyak 20 ekor per kandang uji. Probandus yang digunakan adalah tangan dari relawan yang berjenis kelamin perempuan sebanyak 4 orang.

\section{Bahan}

Bahan yang digunakan: Rimpang jahe (Zingiber officinale, Roxb) yang dibeli dari Pasar Beringharjo DIY, daun sere (Cymbopogon citratus (D.C) Stapf) yang diperoleh dari desa Ceureng Kabupaten Kulonprogo DIY aquades, etanol 96\% (teknis grade), larutan gula $10 \%$, asam stearat, malam putih, vaselin putih, trienolamin, propilen glikol.
Jalannya Penelitian

\section{Isolasi minyak atsiri}

Minyak atsiri diperoleh dengan metode destilasi uap dan air. Minyak atsiri hasil destilasi diukur volumenya dan ditampung pada wadah gelap dan tertutup rapat, dilapisi alumunium foil agar terlindung dari cahaya, serta disimpan ditempat yang sejuk.

\section{Pembuatan vanishing cream (krim) minyak atsiri sere dan rimpang jahe}

Proses pembuatan vasnishing cream minyak atsiri rimpang jahe dan sere dibuatberdasarkan formula standar vanishing cream seperti formula dibawah ini. Formula standar krim menurut Martin, 1993. Formula krim minyak atsiri sere dan jahe.

Krim dibuat dengan cara melelehkan malam putih, asam sterarat dan vaselin putih diatas penangas air pada suhu $75^{\circ} \mathrm{C}$. Selain itu trietanolamin dan propilenglikol dilarutkan dalam air hangat suhu $75^{\circ} \mathrm{C}$. Campuran TEA dan propilenglikol masukkan kedalam lelehan malam putih, asam stearat dan vaselin putih, campuran tersebut diaduk dalam mortir hangat hingga homogen. Setelah krim dingin ditambahkan masing-masing minyak atsiri rimpang jahe atau sere sesuai dengan konsentrasinya dapat dilihat pada Tabel I.

Tabel I. Formula vanishing cream minyak atsiri sere dan jahe

\begin{tabular}{lcccccc}
\hline & \multirow{2}{*}{ Bahan } & \multicolumn{5}{c}{ Formula Vanishing Cream(g) } \\
\cline { 2 - 6 } & FI & FII & FIII & FIV & FV & FVI \\
\hline Asam stearat & 1,15 & 1,15 & 1,15 & 1,15 & 1,15 & 1,15 \\
Malam putih & 0,15 & 0,15 & 0,15 & 0,15 & 0,15 & 0,15 \\
Vaselin putih & 0,61 & 0,61 & 0,61 & 0,61 & 0,61 & 0,61 \\
TEA & 0,12 & 0,12 & 0,12 & 0,12 & 0,12 & 0,12 \\
Propilenglikol & 0,61 & 0,61 & 0,61 & 0,61 & 0,61 & 0,61 \\
Aquadest ad & 5 & 5 & 5 & 5 & 5 & 5 \\
Minyak atsiri sere (mL) & 0,31 & 0,63 & 0,75 & - & - & - \\
Minyak atsiri Jahe (mL) & - & - & - & 1 & 2 & 4 \\
\hline Keterangan : & \multicolumn{7}{c}{ F IV } & : Formula krim minyak atsiri jahe 6,25\% v/b \\
F I : Formula krim minyak atsiri sere 20\% v/b & : F V & : Formula krim minyak atsiri jahe 12,5\% v/b \\
F II : Formula krim minyak atsiri sere 30\% v/b & F VI & : Formula krim minyak atsiri jahe 25\% v/b
\end{tabular}


3. Uji sifat fisik dan aktivitas repelan vanishing cream minyak atsiri rimpang jahe dan sere.

\section{a. Uji daya sebar}

Setengah $(0,5)$ gram sediaan repelan diletakkan diatas kaca bulat berskala, kemudian ditutup dengan menggunakan kaca bulat yang tidak berskala yang telah diketahui bobotnya. Setelah 1 menit, dicatat diameter penyebarannya dan dilanjutkan dengan menambahkan beban sebesar 50 gram, 100 gram. Dicatat luas diameter penyebaran krim dan replikasi dilakukan sebanyak 3 kali.

\section{b. Uji daya lekat}

Uji daya lekat dilakukan dengan cara 0,5 gram sediaan krim diratakan pada objek glas dengan ukuran kurang lebih $3 \mathrm{~cm} \times 2 \mathrm{~cm}$, kemudian ditutup dengan objek glass lain, ditekan dengan beban seberat $1 \mathrm{~kg}$ selama 5 menit. Objek glass dipasang pada alat uji dilepas dengan beban seberat 80 gram dan waktu yang diperlukan untuk memisahkan kedua objek glass tersebut dicatat. Pengujian dilakukan sebanyak 5 kali untuk masing-masing konsentrasi.

\section{c. Uji aktivitas repelan}

Sebanyak 20 ekor nyamuk Aedes aegypti betina dewasa yang dipuasakan dimasukkan dalam sangkar berukuran $20 \mathrm{~cm}$ x $20 \mathrm{~cm}$ x 20 cm dengan lubang sirkuler berdiameter $15 \mathrm{~cm}$. Uji ini menggunakan tangan probandus yang diolesi krim repelan dimana sebelumnya harus dipastikan bebas dari pengaruh bahan kimia lainnya dengan cara dicuci dengan sabun, kemudian dibilas dengan etanol $96 \%$ dan didiamkan selama \pm 2-3 menit.

Uji repelan mengacu pada metode penelitian "Comparative Efficacy of Insect Repellent against Mosquito Bites” oleh Fradin dan Day (2002) yang dimodifikasi waktu pengamatan hinggapnya nyamuk. Pengujian dihentikan jika nyamuk telah hinggap. Jika efek repelan sediaan diperoleh lebih dari 4 jam, maka pergelangan tangan dimasukkan dalam sangkar selama 1 menit dengan selang waktu 1 jam selama 4 jam, kemudian lanjutkan dalam selang waktu 15 menit hingga nyamuk hinggap. Jika nyamuk menempel tapi tidak menggigit (hal ini merupakan tanda bahwa efek repelan mulai menurun) interval waktu diturunkan menjadi 5 menit. Pada masing-masing pengujian dilakukan replikasi sebanyak 3 kali. Semua perlakuan dilakukan pada pagi hari sampai siang hari (pukul 8.00-11.00) mengikuti perilaku nyamuk Aedes aegypti.

\section{Analisis Data}

Data waktu aktivitas repelan dan data hasil uji sifat fisik (daya lekat, daya sebar dan viskositas) repelan diuji homogenitas dan test Kolmogorov-smirnov dengan SPSS versi 16. Bila data terdistribusi normal pada test Kolmogorov-smirnov $(\alpha \geq 0,05)$ dan homogen pada uji homogenitas $(\alpha \geq 0,05)$, maka dilakukan uji parametrik one way Anova dan post hock test. Apabila tidak sesuai dengan ketentuan tersebut, dilanjutkan uji non parametrik KruskalWalls dan Mann Whitney. Data berbeda bermakna bila pada uji parametrik atau uji non parametrik $\alpha \leq 0,05$.

\section{HASIL DAN PEMBAHASAN}

Hasil uji sifat fisik dan daya repelan dari krim minyak atsiri sere dan jahe dapat dilihat pada Tabel II.

\section{Uji daya sebar krim}

Hasil uji daya sebar menunjukkan bahwa ada perbedaan konsentrasi minyak atsiri sere maupun jahe dalam krim masing-masing formula. Pada Tabel II menunjukkan bahwa formula IV dengan kandungan minyak atsiri jahe sebesar $6,25 \% \mathrm{v} / \mathrm{b}$ memiliki rata-rata 
Tabel II. Hasil uji sifat fisik dan daya repelan krim

\begin{tabular}{|c|c|c|c|c|c|c|}
\hline \multirow{2}{*}{ Sifat Fisik } & \multicolumn{6}{|c|}{ Formula } \\
\hline & F I & F II & F III & F IV & F V & F VI \\
\hline $\begin{array}{c}\text { Daya Sebar } \\
\left(\mathrm{cm}^{2}\right)\end{array}$ & $64,13 \pm 4,56$ & $62,41 \pm 4,60$ & $56,32 \pm 14,78$ & $71,69 \pm 1,76$ & $68,10 \pm 4,24$ & $\begin{array}{c}62,94 \pm \\
0,46\end{array}$ \\
\hline $\begin{array}{l}\text { Daya Lekat } \\
\text { (detik) }\end{array}$ & $0,90 \pm 0,03$ & $0,60 \pm 0,02$ & $0,46 \pm 0,04$ & $1,35 \pm 0,15$ & $0,65 \pm 0,02$ & $\begin{array}{c}0,07 \pm \\
0,02\end{array}$ \\
\hline $\begin{array}{l}\text { Daya } \\
\text { Repelan } \\
\text { (detik) }\end{array}$ & $54,71 \pm 2,26$ & $25,17 \pm 2,04$ & $3014,2 \pm 20,16$ & $967 \pm 15,84$ & $1013,8 \pm 23,30$ & $\begin{array}{l}2826,2 \\
\pm 11,39\end{array}$ \\
\hline
\end{tabular}

daya sebar yang paling tinggi, yaitu $71,69 \pm 1,76 \mathrm{~cm}^{2}$, sedangkan formula III dengan konsentrasi minyak atsiri sere sebesar $40 \% \mathrm{v} / \mathrm{b}$, memiliki rata-rata daya sebar paling rendah, yaitu 56,32 $\pm 14,78 \mathrm{~cm}^{2}$. Hasil uji statistik menunjukkan hasil berbeda tidak signifikan antar formula I sampai formula VI memilik nilai $\mathrm{P}>0,05$, artinya bahwa daya sebar krim formula I sampai formula VI memiliki kemampuan daya sebar yang sama, walaupun konsentrasi minyak atsiri sere dalam krim dua kali lebih banyak dibandingkan minyak atsiri jahe. Grafik daya sebar krim dapat dilihat pada Gambar 1.

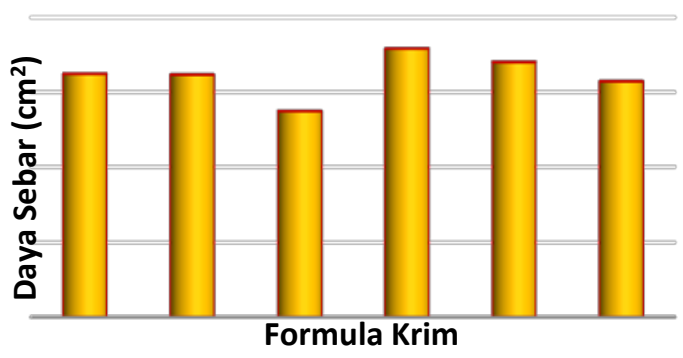

Gambar 1. Grafik daya sebar krim

Faktor yang mempengaruhi hal ini adalah adanya perbedaan densitas minyak atsiri sere dengan jahe. Menurut SNI densitas minyak atsiri sere antara 0,8522-0,8867 $\mathrm{g} / \mathrm{mL}$ (Muyassaroh, 2012), sedangkan densitas minyak atsiri jahe adalah 0,936 g/mL (Banerje, dkk., 2011).
Densitas minyak atsiri menunjukkan kerapatan jenis antar partikel, dimana dengan semakin besar densitasnya maka viskositas semakin besar. Minyak atsiri jahe memiliki densitas lebih besar dibandingkan minyak atsiri sere sehingga meskipun dengan konsentrasi dua kali jumlah minyak atsiri jahe tetap memiliki daya sebar yang sama.

\section{Uji Daya Lekat Krim}

Hasil uji daya lekat dapat dilihat pada Tabel II, menunjukkan bahwa formula IV dengan konsentrasi minyak atsiri jahe 6,25\%v/b memiliki daya lekat yang paling lama dibandingkan formula lainnya. Hal ini disebabkan karena jumlah minyak atsiri yang terkandung dalam krim lebih kecil dibandingkan formula lainnya sehingga mempengaruhi viskositas, yaitu semakin besar.

Daya lekat paling singkat terjadi pada formula VI dengan konsentrasi minyak atsiri jahe $25 \% \mathrm{v} / \mathrm{b}$, yaitu $0,07 \pm 0,02$ detik, walaupun konsentrasi minyak atsiri yang terkandung dalam krim masih lebih kecil dibandingkan dengan FI, FII dan FIII, akan tetapi kemampuan daya lekat paling rendah karena pada konsentrasi tersebut keadaan krim mengalami creaming, sehingga basis krim dengan minyak atsirinya tidak tercampur homogen dan cenderung memisah. Krim dengan minyak atsiri sere cenderung lebih stabil dan baik 
dibandingkankan krim jahe. Hasil uji daya lekat krim dapat dilihat pada Gambar 2.

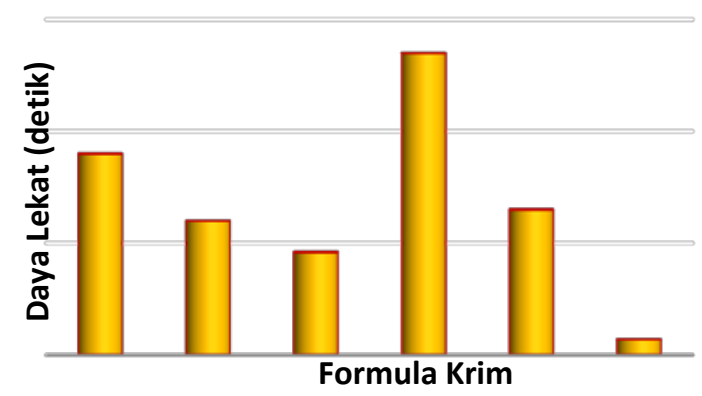

Gambar 2. Grafik daya lekat krim

Hasil uji statistik anova menunjukkan hasil berbeda signifikan antar kelompok formula kecuali pada formula II dengan formula $\mathrm{V}$, menunjukkan perbedaan yang tidak signifikan.

\section{Uji aktivitas repelan vanishing krim minyak atsiri rimpang jahe dan sere.}

Hasil uji aktivitas repelan krim minyak atsiri sere dan jahe dapat dilihat pada Tabel II, dimana seluruh formula memiliki efek repelan. Pada formula III dengan konsentrasi minyak atsiri sere $40 \% \mathrm{v} / \mathrm{b}$ menunjukkan efek repelan yang paling baik dibandingkan formula lainnya dengan efek repelan tertinggi, yaitu sebesar 3014,2 $\pm 20,16$ detik ( 50,24 menit) sedangkan formula VI dengan krim minyak atsiri jahe 25\%v/b memberikan efek repelan sebesar 2826,2 $\pm 11,393$ detik ( 47,10 menit), sedangkan formula IV dan V rata-rata efek repelan masih dibawah 20 menit dan formula I dan II, rata-rata waktu repelannya kurang dari 1 menit.

Kandungan dalam minyak sere yang memiliki kemampuan repelan adalah sitronellal dan geraniol. Menurut Muyassaroh, 2012, kandungan sitronellal dan geraniol dapat ditingkatkan dengan proses pengadukan dan isolasi dengan penambahan natrium bisulfit sehingga kadar sitronellal meningkat menjadi 40,35\% dari awalnya 34,43\% dan kadar geraniol 40,26\% dari awalnya 18,99\%. Pada minyak atsiri jahe yang memiliki kemampuan repelan adalah oleoresin yang mengandung gingerol, shogaol, dan resin. Kandungan oleoresin dalam minyak atsiri jahe 3-4\%, dimana memiliki rasa pedas. Selain mengandung oleoresin, minyak atsiri jahe juga mengandung zingiberen dan zingiberol 1-3\%. Zingiberen dan zingiberon bersifat mudah menguap dan baunya harum khas jahe (Ketaren dan Djatmika,1978). Grafik daya repelan antar formula dapat dilihat pada Gambar 3.

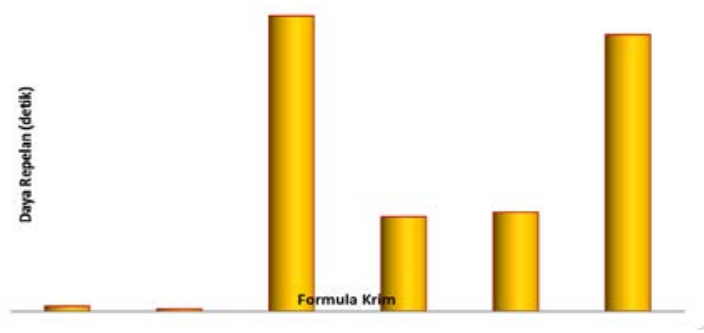

\section{Gambar 3. Grafik daya repelan krim}

Hasil uji statistik dari daya repelan antar kelompok menunjukkan hasilnya $\mathrm{P}=0,00$, artinya $\mathrm{P}<0,05$ yang berarti ada perbedaan antar kelompok perlakuan, kecuali untuk formula I dan II memiliki hasil yang berbeda tidak signifikan dan formula IV dan V memiliki efek repelan yang sama.

\section{KESIMPULAN}

Formula krim yang mengandung minyak atsiri sere sebesar $40 \% \mathrm{v} / \mathrm{b}$ memiliki sifat fisik yang lebih stabil dan baik, yaitu daya sebar 56,32 $\pm 14,78 \quad \mathrm{~cm}^{2}$; daya lekat 0,46 $\pm 0,04$ detik dan kemampuan daya repelan yang paling tinggi dibanding formula lainya sebesar 3014,2 $\pm 20,16$ detik. 


\section{DAFTAR PUSTAKA}

Anonim. 1985. Tanaman Obat Indonesia. Departemen Kesehatan Republik Indonesia :Jakarta.

Anonim. 2007. Tanaman Pengusir Nyamuk. http://www.HarianGlobal.com/news. 12 Agustus 2014.

Banerjee., S., H.I Mullick dan J. Banerjee, 2011, Zingiber officinale : A Natural Gold, International Journal of Pharma and Bio Sciences, vol : 2 ; issues :1; ISSN :09756299 : 283-294.

Fradin, S.M., dan Day, F.D, 2002, Comparative Efficacy of Insect Repellents against Mosquito Bites, The New England Journal of Medicine, Chapel Hill Dermatology, Vol.347 : 13-18.

Ketaren, S. dan Djatmika. 1978. Minyak Atsiri, Bersumber Dari Batang dan Akar. Departemen Teknologi Hasil Pertanian. IPB. Bogor.

Muyassaroh, 2012, Sitronellal Dari Minyak Sereh Wangi Dengan Variasi Kecepatan
Pengadukan Dan Penambahan Natrium Bisulfit, Jurusan Teknik Kimia Fakultas Teknologi Industri ITS, Malang.

Martin, A., J. Swarbrick dan A. Cammarata, 1993, Farmasi Fisik : Dasar-dasar Farmasi Fisik dalam Ilmu Farmasetik. Edisi Ketiga. Penerjemah : Yoshita. Jakarta : UI-Press.

Thavara., U., A. T., Payu Bhakdeenuan, Wongsinkongman., P. , J. B. Thidarat Boonruad, Pranee Chavalittumrong., Komalamisra., N,, et al, 2007, "Repellent Activity Of Essential Oils Against Cockroaches

(Dictyoptera: Blattidae,Blattellidae, And Blaberidae) In Thailand." Southeast Asian J Tropical Medical Public Health 38.

Yuliani, S; Usmiati. S dan Nurdjannah. N, 2005, Efektivitas Lilin Penolak Lalat (Repelen) Dengan Bahan Aktif Limbah Penyulingan Minyak Nilam, Journal Pascapanen, Balai Besar Penelitian dan Pengembangan Pascapanen Pertanian; vol : 2(1) : 1-10. 